\title{
NEXUS BETWEEN CONSUMER WELFARE AND MARSHALIAN'S DEMAND FUNCTION; EVIDENCE FROM PAKISTAN
}

\author{
Gulzar Ali", Sara Rafiq ${ }^{\dagger} \&$ Ansa Javed
}

\begin{abstract}
Consumer welfare and their satisfaction is the primary and basic objective of any government, policy makers and economists. The theory of economics encircles from welfares of the consumers. In this regard, the demand function has persuasive role in determining the welfare through purchasing power. That's why, the consumer welfare is measured from Marshallian's demand through Indirect Utility Function during 1980-2017 for Pakistan. The variables are stationary at level and in analytical technique, the NLS and ARMA (Least Regression Analysis) method was operative through econometric views (E-Views) software. The result indicates that income of the consumer has significant and positive effect, while price of goods has significantly negative effect on the consumer welfare and utility in case of Pakistan. Further, the long run association of consumption, income and consumer welfare was found. This study recommends that incremental efforts are required by the government to bring stability in the prices of goods, policies must aim and focus on provision of employment and income generating activities, control of income inequality and minimize income class disparities to maximization welfare of the individuals living in different regions and in societies of Pakistan.
\end{abstract}

Keywords: Marshallian Demand Function, Consumer Welfare, Indirect Utility Function, Least Square Regression Method

\footnotetext{
Department of Economics, Islamia College, University of Peshawar. (E-mail: gulzaricup@yahoo.com)

Department of Economics, Women University Mardan, KPK, Pakistan (E-mail: rafiqsara@yahoo.com)

* Women University Mardan, KPK, Pakistan (E-mail:ansaj165@gmail.com)
} 


\section{Introduction and Background}

Micro economics predominantly consists of two theories: the consumer and producer theory. The classical school of thought supports producer theory as stated "supply creates its own demand". The Keynesian school of thoughts supports the consumer theory as stated "demand creates its own supply". If vigilantly analyzed, both theories are sturdily dependent with each other, but consumer theory gain auxiliary importance and meditation, because producers itself consumer too, as they consume and demand both the services and goods in order to gain utility. The solitary objective of the consumer theory is to maximize consumer satisfaction or consumer utility. Utility or satisfaction that consumer obtains depend on consumption of commodities as well of services, and, the consumption of bundles of goods and consumed services depend upon the income and prices. This concept is known as Indirect Utility Function.

The consumer utility is based on the income and price of goods; consequently, consumer utility estimates consumer behavior towards purchasing goods within their budget constrain. The budget constrains shows willingness and ability of consumer to buy the goods and service at a given level of price of goods and income of the consumer. Commodities or goods for which, consumer has willingness to consume and the ability to pay determine welfare of consumers. The intact process in which the consumer takes decision concerning demand for goods keeping glance on his budget constrain for attaining of utility conclude the consumer behavior. Now a day's behavioral economics is the most debating and provoking issue, as this subject matter is mostly related to day to day behavior and decision of the individuals.

The consumer demand for goods and buying behavior stanch with the pragmatic expenditure function consequent and derivative from the individual's demand. In the long run the consumer welfare and Individual's demand function varies with relative change in price of goods and services (Slutsky Equation). Therefore, the flexible demand function with relative price changes is desirable to observe the consumer behavior whilst deriving the consumer welfare from the individual's demand functions (Zhao et al., 2012). (Barnet and Jonas, 1983; and Gallant and Souza, 1991) worked on the flexible demand system articulated that restricted demand function is just succession of non-parametric demand function, because don't have strong evidence of micro economic theory. They concluded that it is impossible to study the consumer behavior and welfare as well as to derive the consumer utility from the restricted demand function. Slutsky symmetry (1880-1948) is an important contribution deriving utility from the price change effect while keeping the income effect constant directly.

Though, income of the consumer is the most important element of the consumer theory. But this component is most volatile variable of the 
consumer welfare and demand as it varies from individuals to individuals, countries to countries and even among the earning group. The income elasticity too varies along with goods and income groups. Although income plays the major role in consumer demand, but it's very difficult to predict and estimate the consumer behavior and welfare without counting the relative price effect. The important contributions in this regard originated from the work of (Jorgenson et al., 1982; Deaton and Muellbauer, 1980; and Muellbauer, 1976), but these studies gave more weight to working-lesser curve. The working-lesser and Engle curve solitary via price effect couldn't represent factual and realistic picture of the consumer behavior (Allcott, 2013). It doesn't intensively explain welfare of the consumer without considering the expenditure effect. Many researchers and economists follow a line of investigation, which refocuses attention towards the income effect with an additional obsession of expenditure approach being obligatory for derivation of the consumer utility for some goods.

\section{Scope and Significance of the Study}

This research study deriving the utility and consumer welfare, using the Marshallian Demand functions as indirect utility function and substituting it in utility equation. Earlier studies focused on Engle and working-Lesser curve. This study applies the Engle and working-Lesser curve as well as the relative price effect (Slutsky Equation) to observe the consumer behavior towards goods and welfare of the consumer obtained from consumption bundle of goods "Xi" ( $\mathrm{i}=1 \ldots \ldots \ldots . . \mathrm{n})$. This study empirically examines the consumer welfare and indirect utility function for Pakistan, allowing the flexible demand system with stipulation of the price changes of goods "Xi" and income of the consumer.

The Marshallian demand system incorporates both the income and price effect. This research study considering income of the consumer as well as prices of goods in order to derive consumer utility and welfare taking all other things (taste of the consumer, preference, seasonal variation, price of substitutes, class differences etc) as constant. The consumer welfare is taken as percentage share of consumption to GDP. The consumer may maximize their satisfaction (utility) by consuming the bundle of good "Xi" having some price "Px" bear by the consumer from the available income "M". This phenomenon is known as Indirect Utility Function.

\section{Problem Statement}

The developing country like Pakistan that are facing huge unemployment and poverty level, the welfare of the citizen is just a dream. Moreover, the rapid fluctuation in price level and running inflation severely affect the level of demand, purchasing power and welfare of the people 
especially low and middle income groups. As in Pakistan, approximately sixty percent of the people are living below poverty line, which is why it is important to measure the welfare condition of the people especially that are effect and originated from income of the consumer and price of services \& goods.

\section{Study Objective}

The basic study objective is to derive the consumer welfare from Marshallian's demand through indirect utility function (IUF) in case of Pakistan.

\section{Literature Review}

The consumer welfare and consumer behavior are dependent on income of the consumer and price of the demanded goods (McFadden and Zhou, 2015; and Miller, 2011). However, there are some utility based consumer welfare models that concentrate on the income effect and implement gratuitous and unprovoked restrictions on the price effect and its elasticity to demand (Bhattacharya, 2017; and Manig and Moneta, 2014). Notable literature exists on the restriction of the linear expenditure function (Price effect). Some well-known studies regarding the cited concern were (Vatin et al., 2016; Frank et al., 2014; and Chai and Moneta 2010). An Almost Ideal Demand System was derived from the consumer theory to infer and precisely illustrate of the consumer behavior and welfare by (Deaton and Muellbauer, 1980), extended the work of (Richard, 1954). Almost Ideal Demand System model were preferred over the Rotterdam and Translog Model. The main criticism on these models were that these models are generally developed and explaining the linear expenditure model, and didn't satisfy the main axioms of the consumer theory. Whereas, the Almost Ideal Demand System satisfies the axioms of the consumer choice as well as the non-linear model concerning the Engle curve, consumer budget and satisfies homogeneity property (Train, 2015; Kaus, 2012; and Chao and Utgoff 2006).

Various literature are prompt in which the researchers analyzed that with income approach the expenditure approach is necessary for deriving the consumer utility from some goods not all, isn't it repetition of the previous line (Bernheim, 2016; and Chao and Utgoff, 2006). Many studies have instigated strong evidence that Engle curve and working lesser curve doesn't gave a precise representation of the consumer behavior in deriving the utility from some goods. The well-known studies in this regard were (Charles et al., 2009; Bierens and Pott-Buter, 1987; Atkinson et al., 1990; Lewbel, 1991; Blundell et al., 1993; Hilden, 1994; Hausman et al., 1995; and Hardle and Jerison, 1988). 
Witt (2016) pointed out that the consumer welfare solely depended on the behavior of the consumer choices and preferences towards opportunities of goods. The motivational factors in this regard are the income and prices of the demanded goods. Moreover, the paper concluded that an increase in consumption level doesn't guarantee an increase in welfare of the consumer, and that the increase in consumption may be due to increase in price level. Maddison (2001) viewed that an increase in consumption is the result of an increase of world population and per capita income since last decade. Whereas, (Binder, 2010) argued that consumer preferences and consumption invariably assumed by the consumer that solely comply on the utility of the consumer. Sometimes, the consumer expenditure is increased irrespectively of due to an increase in the prices of their preferred goods. However, these invariable preferences are independent of the welfare of most of individuals. The product specification and market efficiency also effect the consume expenditure and welfare (Allenby et al., 2014)

\section{Methodology of the Study}

\section{Area of this Research Study}

This research study is conducted on Pakistan being a developing country having approximately 200 million of populations. The standard of living is not much satisfactory as the Human Development Index (HDI) is low. The consumer income has much variation due to high income inequalities as showing by Gini-Coefficient value of an average 30 from 1990- 2014. The last two decades have experienced too much discrepancy in the prices of goods. The income class differences are very high. High income group becomes rich to a large extent but sixty percent $(60 \%)$ of the individuals are poor and falls in lower income group, if estimated on the basis of earning two dollars (\$2) per day.

\section{Data Analysis}

This study consists on time series analysis during 1980-2017, because the data prior to 1980 are not available for the variables selected for this research study. The data are collected from the global economy data indicator, State Bank of Pakistan (SBP), Households Integrated Economics Survey (HIES), Pakistan Social and Living Standard Measurement (PSLM) and World Development Indicator (WDI).

\section{The Consumer Welfare Model}

Consumer welfare is estimated from the consumption of goods. When the price of goods increases the welfare of the consumer falls and it raises as the income level of the consumer rises. In simple words, according to demand theory the consumer worse off if the price level increase and better off if the income level increases. Utility that the consumer obtained depends 
on consumption of commodities and available services and consumption of services and commodities depend upon the income and prices. So, the welfare of the consumer is estimated from the level of satisfaction and the utility obtained from consumption of mostly goods (may be X) and services. This concept is known as indirect utility function that derives from the level of income of the consumer and prices of commodities or goods. The function is

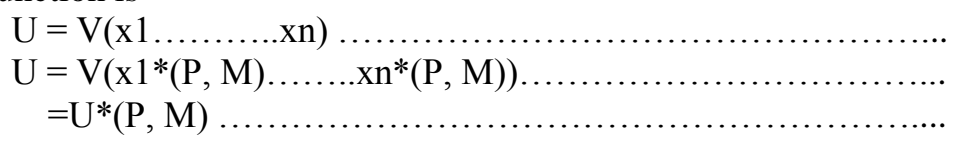

As the income of the consumer increases other things remain constant, the purchasing power of the consumer also increases. So, indirect utility function (IUF) is monotonic increasing in income of the consumer. Now by applying the partial derivative of equation (2.3) with respect to available income to the consumer " $\mathrm{M}$ ", keeping the price of goods $(\mathrm{P})$ constant, that is;

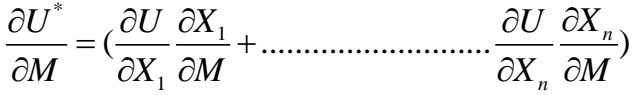

$$
\begin{aligned}
& \frac{\partial U^{*}}{\partial M}=\left(\lambda P_{1} \frac{\partial X_{1}}{\partial M}+\ldots \ldots \ldots \ldots \ldots \ldots \ldots \ldots \ldots+. . .+\lambda P_{n} \frac{\partial X_{n}}{\partial M}\right)
\end{aligned}
$$

Equation (2.4) shows that utility (U) depend upon the consumption of good (X1) and consumption of good (X1) depend upon the income of the consumer (M). In equation (2.5) “" " is the Marginal Utility ${ }^{\S}$, that is

$\lambda=M U=\frac{\partial U}{\partial X}=\frac{U_{i}}{P_{i}}$

Taking $" \lambda »$ common

$$
\begin{aligned}
& \frac{\partial U^{*}}{\partial M}=\lambda\left[\partial\left(\frac{P_{1} X_{1}+\ldots \ldots \ldots \ldots \ldots .+P_{n} X_{n}}{\partial M}\right) .\right. \\
& \frac{\partial U^{*}}{\partial M}=\lambda=\frac{U_{i}^{+}}{P_{i}^{+}}>0 \ldots \ldots \ldots \ldots \ldots \ldots \ldots \ldots \ldots \ldots \ldots \ldots \ldots . . .
\end{aligned}
$$

Demand for good is inversely proportional to the price level, if other things remain constant. As the prices of goods increases the demand for

\footnotetext{
$\S$ It is define as "Change in Total utility due to one additional or extra unit of consumption of goods (X)" $\cdot M U=\frac{\Delta U}{\Delta X}$
} 
goods falls and the consumer feels worse off. So, indirect utility function (IUF) is monotonic decreasing in prices of the goods (X). after taking the partial derivative of (2.3) with respect to Price of goods (P) keeping the income of the consumer (M) constant, that is;

$\frac{\partial U^{*}}{\partial P_{1}}=\left(\frac{\partial U^{*}}{\partial X_{1}} \frac{\partial X_{1}}{\partial P_{1}}+\ldots \ldots \ldots \ldots \ldots . . .+\frac{\partial U^{*}}{\partial X n} \frac{\partial X n}{\partial P n}\right)$

$\frac{\partial U^{*}}{\partial P_{1}}=\left(U_{1} \frac{\partial X_{1}}{\partial P_{1}}+\ldots \ldots \ldots \ldots \ldots \ldots+U_{n} \frac{\partial X n}{\partial P n}\right) \ldots$

$\frac{\partial U^{*}}{\partial P_{1}}=\left(\lambda P_{1} \frac{\partial X_{1}}{\partial P_{1}}+\ldots \ldots \ldots \ldots \ldots \ldots+\lambda P_{n} \frac{\partial X n}{\partial P n}\right)$

Where

$\frac{U_{1}}{P_{i}}=\lambda \ldots \ldots \ldots . . .(2.9 a) \quad$ So, $\lambda P_{i}=U_{1}$

As we know that

$M=\left(P_{1} X_{1}+P_{2} X_{2}+\right.$

Now consider

$\frac{\partial M}{\partial P_{1}}=\partial\left(\frac{P_{1} X_{1}+P_{2} X_{2}+\ldots \ldots \ldots \ldots . . P_{n} X_{n}}{\partial P_{1}}\right) .$.

$\frac{\partial M}{\partial P_{1}}=\left(X_{1}^{*}+P_{1} \frac{\partial X_{1}}{\partial P_{1}}+P_{2} \frac{\partial X_{2}}{\partial P_{1}}+\ldots \ldots \ldots \ldots . . .+P_{n} \frac{\partial X_{n}}{\partial P_{1}}\right)$

$0=\left(X_{1}^{*}+P_{1} \frac{\partial X_{1}}{\partial P_{1}}+P_{2} \frac{\partial X_{2}}{\partial P_{1}}+\ldots \ldots \ldots \ldots+P_{n} \frac{\partial X_{n}}{\partial P_{1}}\right)$

$\left.-X_{1}^{*}=P_{1} \frac{\partial X_{1}}{\partial P_{1}}+P_{2} \frac{\partial X_{2}}{\partial P_{1}}+\ldots \ldots \ldots \ldots+P_{n} \frac{\partial X_{n}}{\partial P_{1}}\right) \ldots$

Substituting in eq (2.10) 
$\frac{\partial U^{*}}{\partial P_{1}}=\lambda\left(-X_{1}^{*}\right)$
$\frac{\partial U^{*}}{\partial P_{1}}=\left(-\lambda X_{1}^{*}\right)$.

So, equation (2.6) shows that consumer welfare is positively related with the income of the consumer and equation (2.16) showing that consumer welfare is negatively related with the price of the goods.

To estimate the consumer welfare and examine their behavior, the indirect utility function be used substituting in Marshallian function in the utility equation derived from equation ( $2.6 \& 2.16)$. The consumer welfare is taken as percentage share of consumption to GDP of Pakistan, the dependent variable. The independent variables selected for this research study are income of the consumer and prices of Goods taking all other things being constant. The theoretical equation of the consumer welfare for this study can be written as;

Consumer Welfare $=\mathrm{f}$ (Income of Consumer, Prices of Goods $)$

The econometric model followed by theoretical equation (2.17) for the consumer welfare is;

ConsumerWelfare $=\beta_{0}+\beta_{1}($ Income $)+\beta_{2}($ Price $)+\mu_{t}$

The sign of the co-efficient of the estimators expected to be;

$\beta_{1}>0, \beta_{2}<0$

The linear with logarithmic form model applied for estimating the consumer welfare from indirect utility function. The variables are regressed through NLS and ARMA (Least Square) regression model run through econometric software E-Views (Econometric Views). The error term are supposed to be normally distributed with the white noise restriction estimated with the subsequent formula; $\left[\mathrm{E}\left(\mathrm{n}_{\mathrm{i}}\right)=0\right.$ whereas, $\mathrm{E}(\eta \mathrm{ni}) 2=\sigma 2 \& \mathrm{E}\left(\mathrm{n}^{\mathrm{i}}\right.$ nj) $=0$ ]

\section{Estimation Procedure and Results}

\section{Unit Root Test and Regression Analysis of the Variables}

The unit root tests often pertain on time series data for finding the spurious relation, integrating factor or uni-variate relation exits or not in the data, however, the imperative aim is to check the stationary of data. Moreover, it also confers on selecting and applying the suitable analytical technique. Generally there are vestiges wary about spurious and outliers in 
time series, for that reason, the researchers strongly recommends unit root test before applying analytical techniques for regression analysis. The most popular unit root test especially for large samples data is the Augmented Dicky-Fuller (ADF) test for the stationarity and selecting the precise tools for regression analysis.

Table 1: Stationary Results of Variables are

\begin{tabular}{lcccc}
\hline \multirow{2}{*}{ Variables } & \multicolumn{2}{c}{$\begin{array}{c}\text { ADF Values at Level with } \\
\text { Intercept }\end{array}$} & \multicolumn{2}{c}{ PP Values at Level with } \\
Intercept
\end{tabular}

Critical value selected at $05 \%$

The unit root test results show that the variables are stationary at level. The critical value of Augmented Dicky-Fuller (ADF) is selected at 05\% significance level. The stipulation where variables have at level are stationarity, NLS and ARMA (Least Square) model are suggested as regression techniques for further analysis. For the estimation analysis of consumer welfare from marshallian function through IUF the NLS and ARMA model is applied and the outcome is given in table (2).

Table 2: Regression Results of Consumer Welfare

\begin{tabular}{|c|c|c|c|c|}
\hline Varibles & $\beta$ values & Std. Err & t-st. value & P. value \\
\hline Constant & 0.423697 & 0.110230 & 3.843746 & 0.000000 \\
\hline Log (Income) & 0.768270 & 0.157786 & 4.869037 & 0.000000 \\
\hline Log (Price) & -0.254688 & 0.075060 & -3.393092 & 0.000000 \\
\hline $\mathbf{R} 2$ & \multicolumn{2}{|c|}{0.897652} & Dur-Watson & 1.862913 \\
\hline Adjusted R2 & \multicolumn{2}{|c|}{0.875278} & Prob. F-Stat & 0.000000 \\
\hline & & & F-Stat Value & 711.1076 \\
\hline
\end{tabular}

The recitation of the intact model for estimation of consumer welfare from Marshallian function through IUF as an evidence of Pakistan is satisfactory showed by the statistics integrated from the NLS and ARMA regression analysis. The p. (F-stat) value is significant at $1 \%$, while F-stat value is (711.108), viewing the premier association and nuance of the model. Approximately $90 \%$ deviation is illuminating the R2 Squared value between 
the variables confirming goodness of fit. The Durbin Watson value, slam to the preferred value, interpreting the negligible probability of serial, spurious and auto-correlation.

Results of the variables co-efficient originated from the regression analysis have significant $\{(\mathrm{t}$-stat and prob. value of the coefficient of variables showing in table (2)\} effect with true expected signs enhanced interpreting consumer welfare model developed for this research study with the assumed hypothesis ${ }^{* *}$.

The explanatory variable included in the study, income of the consumer has positive and significant value indicating momentous effect on the consumer welfare in case of Pakistan. The coefficient result of the consumer welfare revealed that $1 \%$ increase in income of the consumer fetch $0.76 \%$ glowing lustrous amend in the utility and welfare of the consumer. This proves that income of the consumer is monotonic increasing in obtaining utility and welfare of the consumer as assumed during the construction and deriving of the model from utility function by substituting the Marshallian's Demand Function. The outcome of the study is consistent with the study of (Deaton and Muellbauer, 1986; Chai and Moneta, 2010; Kaus, 2012; and Witt, 2016) found that Engle curve is monotonic increasing in Utility of the consumer.

The coefficient of the price of goods has significant negative value, demonstrating the inverse relation with consumer welfare. If price of goods increases, the purchasing power of the consumer falls, leading to decrease in the consumer utility and welfare. The results obtained by the study show that $1 \%$ increase in the price of goods brings $0.25 \%$ decrease in consumer demands for goods. This decrease ultimately affects the utility and welfare of the consumer. It clarifies that price of goods are monotonic decreasing in the utility and welfare of the consumer as supposed in the model. In the earlier studies of (Manig and Moneta, 2014; Baudisch, 2006; and Ruprecht, 2005) have found the inverse effect price of goods with consumption, demand of goods and welfare of the peoples.

The autonomous consumption has also significant and positive value, indicates that it has also positive effect on the utility and welfare of the consumer in case of Pakistan.

For long/short run association between income, consumption and consumer welfare, the Wald test is regressed and (3) indicates long run relation of consumption, income with consumer welfare in case of Pakistan for the selected period of analysis.

\footnotetext{
** Income of the consumer is monotonic increasing \& price of goods have monotonic decreasing in Utility as proved in equation (2.6) \& (2.16).
} 
Table 3: Wald Test Analysis

\begin{tabular}{lccc}
\hline Test Statistic & Value & df & Probability \\
\hline F-statistic & 30.93858 & $(3,22)$ & 0.0000 \\
Chi-square & 92.81573 & 3 & 0.0000 \\
\hline
\end{tabular}

Null Hypothesis: $\mathrm{C}(1)=\mathrm{C}(2)=\mathrm{C}(3)=0$

Null Hypothesis Summary:

\begin{tabular}{ccc}
\hline Normalized Restriction $(=0)$ & Value & Std. Err. \\
\hline & & \\
$\mathrm{C}(1)$ & 0.406558 & 0.162932 \\
$\mathrm{C}(2)$ & 0.315905 & 0.121609 \\
$\mathrm{C}(3)$ & 0.094323 & 0.071274 \\
\hline
\end{tabular}

Restrictions are linear in coefficients.

\section{Stability and Diagnostic Analysis of the Model}

The permanence, normality, reliability and robustness of analysis are checked through diagnostic and stability tests.

For normality of the results Jarque-Bera method is runs and the outcome of J-Bera test indicate the normality and stability of model. Further, showing that variance in the model is constant rejecting the chances of Heteroskedasticity in the model.

\section{Table 4: Normality Result}

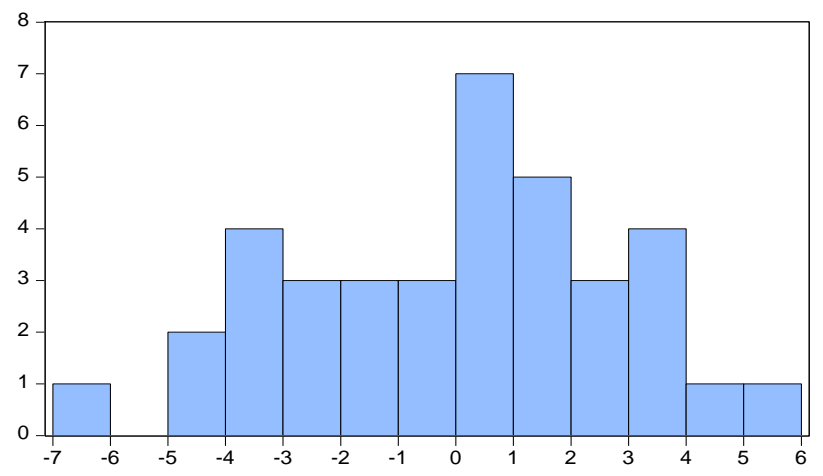

\begin{tabular}{|lc|}
\hline \multicolumn{2}{|l|}{ Series: Residuals } \\
Sample 1977 2013 \\
Observations 37 \\
Mean & $-1.12 \mathrm{e}-14$ \\
Median & 0.498282 \\
Maximum & 5.472707 \\
Minimum & -6.673730 \\
Std. Dev. & 2.830732 \\
Skewness & -0.212323 \\
Kurtosis & 2.410002 \\
& \\
Jarque-Bera & 0.814648 \\
Probability & 0.665428 \\
\hline
\end{tabular}

To check the stability and specification error the CUSUM test is runs and the result in graph (1) indicates that the model isn't agonizes from any type specification error and biasness. 


\section{Graph 1:. CUSUM Specification Test Result}

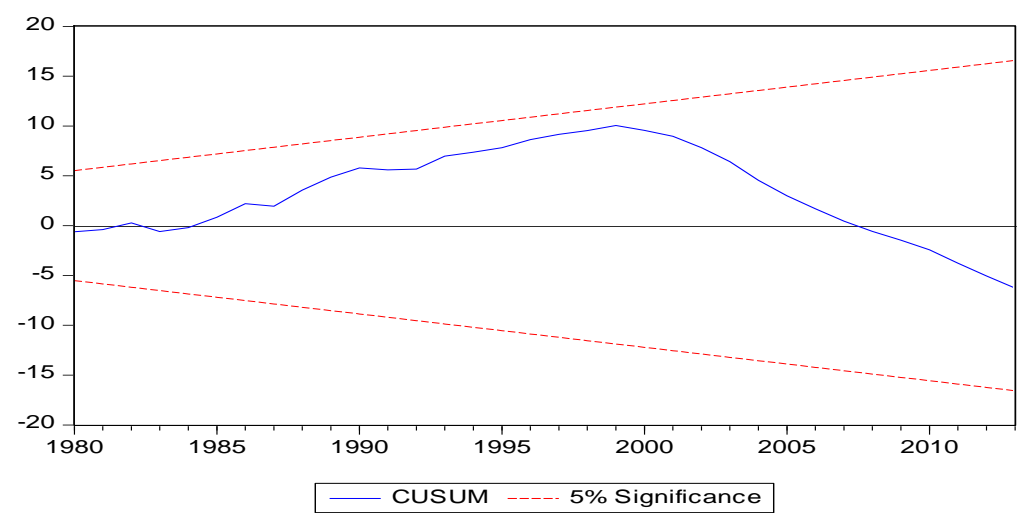

\section{Conclusion}

This research study attempted to briefly elucidate the consumer welfare from Marshallian function through indirect utility function and deliberate the behavior of consumer responses towards the changes in income of the consumer and prices of goods for Pakistan. The study allows flexible demand system, where both price and income are included. These two are the important factors that effect, influence and change the decision of consumer towards buying behavior and demand for goods and service, ultimately leads to affect the utility and welfare of the consumer. However, the findings revealed that income of the consumers has more dominant effect than the prices of goods on consumer behavior and welfare.

\section{Recommendations}

On the basis of the findings, the following recommendations have been suggested by this study

The government needs to increase and provide greater employment opportunities for the increasing welfare of the people

The stable price is necessary as fluctuation in price effect both demand and supply that creates imbalances in the equilibrium

Prices should be controlled to sustain the purchasing power of the people

Further Area of suggestions for researcher

This study suggesting the following area for further research in the scope of current study.

As due to time constraints the whole country (Pakistan) data has taken collectively. In depth analysis on provincial level for better understanding of provincial welfare and comparison would be more beneficial. 
The study may be conducted on rural and urban areas separately as the price of goods and income status are different in rural and urban areas.

\section{References}

Allcott, H. (2013). The Welfare Effects of Misperceived Product Costs: Data and Calibrations from the Automobile Market. American Economic Journal: Economic Policy 5(3), 30-66.

Allenby, G., Brazzell, J., Howell, J., and Rossi, P. (2014). Economic Valuation of Product Features. Quantitative Marketing Economics, 12, 421-456.

Atkinson, A.B., Gomulka, J., and Stem, N.H. (1990). Spending on Alcohol: Evidence from the Family Expenditure Survey 1970-1983. Economic Journal, 100 (42), 808-827.

Barnet, W.A., and Jonas, A. (1983). The Muntz-Szatz Demand System: An Application of a Globally Well Behaved Series expansion. Economics Letters, 11 (4), 337-342.

Baudisch, F. (2006). Product Innovation, Consumer Heterogeneity and Market Growth, Unpublished PhD. Thesis, University of Jena

Bernheim, D. (2016). The Good, the Bad, and the Ugly: A Unified Approach to Behavioral Welfare Economics. Journal of Benefit Cost Analysis, 7(1), 12-68.

Bhattacharya, D. (2017). Empirical Welfare Analysis for Discrete Choice: Some General Results. Cambridge University working paper.

Bierens H.J., and Pott-Buter H.A. (1987). Specification of Household Engel Curves by Nonparametric Regression. Econometric Reviews, 9 (2), 123184.

Binder, M. (2010). Elements of an Evolutionary Theory of Welfare. Routledge, London

Blundell, R.W., Pashardes, P., and Weber, G. (1993). What Do We Learn about Consumer Demand Patterns from Micro-Data? American Economic Review, 83 (3), 570-597.

Chai, A., and Moneta, A. (2010). Retrospectives: Engel curves. Journal Economics Perspective 24, 225-240

Chao, E.L., and Utgoff, K.P. (2006). 100 Years of U.S. consumer spending Data for the Nation, New York City, and Boston, Report 991, U.S. Bureau of Labor Statistics

Charles, K.K., Hurst, E, and Roussanov, N. (2009) Conspicuous consumption and race. Quarterly Journal Economics, 124, 425-467

Deaton, A.S., and Muellbauer, J. (1980). An Almost Ideal Demand System. American Economic Review, 70 (3), 312-336.

Frank, R.H., Levine, A.S., and Dijk, O. (2014). Expenditure Cascades. Revolution Behavioral Economics 1, 55-73. 
Gallant, R.A., and Souza, G. (1991). On the Asymptotic Normality of Fourier Flexible Form Estimates. Journal of Econometrics, 30 (1), 329-353.

Hardle, W., and Jerison, M. (1988). The Evolution of Engel Curves over Time. Discussion Paper No. A-178, SFB 303, University of Bonn.

Hausman, J.A., Newey, W.K. and Powell, J.L. (1995). Nonlinear Errors in Variables: Estimation of Some Engel Curves. Journal of Econometrics, 65 (5), 205-233.

Hilden, B.W. (1994). Market Demand: Theory and Empirical Evidence. Princeton University Press, Princeton New Jercy.

Jorgenson, D.W., Lau, L.J. and Stoker, T.M. (1982). Aggregate Consumer Behavior and Household Equivalence Scales. Journal of Business \& Economic Statistics, 5(2), 219-232.

Kaus, W. (2012). Beyond Engel's Law - Pursuing an Engelian approach to welfare - A Cross Country Analysis. Jena Economic Research Papers, 2012-028, University of Jena.

Lewbel, A. (1991). Full Rank Demand Systems. International Economic Review, 31 (2), 289-300.

Maddison, A. (2001). The World Economy: a Millennium Perspective. OECD, Paris.

Manig, C., and Moneta, A. (2014). More or Better? Measuring Quality versus Quantity in Food Consumption. Journal of Bio-economics, 16, $155-178$.

McFadden, D., and Zhou, B. (2015). Measuring Lost Welfare from Poor Health Insurance Choices. Schaeffer Center, USC.

Miller, K. (2011). How Should Consumers' Willingness to Pay Be Measured? An Empirical Comparison of State-of-the-Art Approaches. Journal of Marketing Research, 48(1), 172-184.

Muellbauer, J. (1976). Community Preferences and the Representative Consumer. Econometrica, 44 (5), 979-999.

Richard, S. (1954). The Measurement of Consumers Expenditure and Behavior in the United Kingdom. Cambridge University Press, Vol. 1 (1954).

Ruprecht, W. (2005). The Historical Development of the Consumption of Sweeteners - a Learning Approach. Journal Evolution Economics, 15, 247-272.

Train, K. (2015). Welfare Calculations in Discrete Choice Models when Anticipated and Experienced Attributes Differ: A Guide with Examples. Journal of Choice Modeling, 16, 15-22.

Vatin, F., Simonin, J., and Marco, L. (2016). The Works of Jules Dupuit: Engineer and Economist of the French XIXth Century, Edi-Gestion, 1 (1).

Witt, U. (2016). The Evolution of Consumption and its Welfare Effects. Journal of Evolution Economics, 27, 273-293

Zhao, Y., Kockelman, K., and Karlstrom, A. (2012). Welfare Calculations in Discrete Choice Settings: The Role of Error Term Correlation. Transport Policy 19(1), 76-84. 